\title{
In vitro and in vivo anti-Vibrio vulnificus activity of psammaplin A, a natural marine compound
}

\author{
BYUNG CHEOL LEE ${ }^{1}$, ARIM LEE ${ }^{1}$, JEE HYUNG JUNG ${ }^{2}$, SANG HO CHOI $^{3}$ and TAE SUNG KIM ${ }^{1}$ \\ ${ }^{1}$ Department of Life Sciences, College of Life Sciences and Biotechnology, Korea University, Seoul 136-701; \\ ${ }^{2}$ Department of Pharmacy, Pusan National University, Geumjeong-gu, Busan 609-735; \\ ${ }^{3}$ National Research Laboratory of Molecular Microbiology and Toxicology, Department of Agricultural Biotechnology, \\ Seoul National University, Seoul 151-921, Republic of Korea
}

Received July 9, 2015; Accepted July 6, 2016

DOI: $10.3892 / \mathrm{mmr} .2016 .5522$

\begin{abstract}
Vibrio vulnificus is known to induce severely fulminant and fatal septicemia in susceptible hosts. In the present study, the antimicrobial activity of natural marine product-derived compounds against $V$. vulnificus, were investigated in vitro and in vivo. Twelve pure compounds were isolated from natural marine products and their inhibitory effects on $V$. vulnificus-induced cytotoxicity were determined in INT-407 cells. Among the 12 pure compounds tested, treatment with psammaplin A significantly suppressed V. vulnificus-induced cytotoxicity in INT-407 cells. Notably, treatment with psammaplin A $(5-50 \mu \mathrm{g})$ had improved survival rates compared with that in the untreated mice, when the mice were infected with $V$. vulnificus intraperitoneally. In addition, the bacterial load of $V$. vulnificus in several tissues (spleen, liver and small intestine) was significantly lower in psammaplin A-treated mice than in untreated mice. Furthermore, psammaplin A treatment significantly suppressed the growth of $V$. vulnificus. Taken together, these results indicate that psammaplin A may be a potential agent for the prevention and treatment of $V$. vulnificus infections.
\end{abstract}

\section{Introduction}

Vibrio vulnificus is a gram-negative bacterium, is known to cause primary sepsis and gastroenteritis in humans. Following an infection with $V$. vulnificus, the disease proceeds rapidly, resulting in extensive cellular damage. Additionally, the consumption of contaminated shellfish or wound infection with V. vulnificus can induce fatal septicemia in susceptible individuals with chronic liver disease (1). A variety

Correspondence to: Professor Tae Sung Kim, Department of Life Sciences, College of Life Sciences and Biotechnology, Korea University, 145 Anam-ro, Seongbuk-gu, Seoul 136-701, Republic of Korea

E-mail: tskim@korea.ac.kr

Key words: Vibrio vulnificus, psammaplin A, antimicrobial activity of virulence factors produced by $V$. vulnificus can induce septic shock, which is often fatal. Putative virulence factors, including capsular polysaccharides (2,3), siderophores (4), hemolysin (5), matrix metalloproteinase $(6)$, flagella $(7,8)$ and RtxA toxin (9-11) have been reported in vivo and in vitro. These virulence factors may induce the persistent production of proinflammatory mediators, such as interleukin (IL)-1 $\beta$, IL-6, IL-8, tumor necrosis factor (TNF)- $\alpha$ and nitric oxide in the host $(12,13)$. Therefore, highly active antimicrobial agents are required for the efficient treatment of $V$. vulnificus infections. In this study, the anti- $V$. vulnificus activity of psammaplin A was investigated in vitro and in vivo.

Psammaplin A is a natural marine product isolated from sponges, such as Poecillastra sp., Jaspis sp. and Psammaplysilla sp. (14,15). Psammaplin A is known to possess antimicrobial (16), antitumor and cytotoxic activities against several cell lines, including the P388 leukemia cell line $(14,15)$, as well as lung, ovarian and colon cancer (17). It was also reported to have inhibitory activities against DNA gyrase, DNA topoisomerase, farnesyl protein transferase and leucine aminopeptidase (16,18-22). Previous studies showed that psammaplin A possesses an antimicrobial effect against methicillin-resistant Stapylococcus aureus (MRSA) $(16,23,24)$. However, the effects of psammaplin A on $V$. vulnificus infection in vitro and in vivo have not been investigated.

In this study, the antibacterial activity of psammaplin A against $V$. vulnificus as well as its suppressive effects against the cell cytotoxicity induced by $V$. vulnificus were examined in vitro and in vivo.

\section{Materials and methods}

Animal cell culture and chemicals. The INT-407 human epithelial cell-line (ATCC CCL-6) was purchased from the American Type Culture Collection (Manassas, VA, USA), and maintained at $37^{\circ} \mathrm{C}$ under $5 \% \mathrm{CO}_{2}$ in Minimum Essential Medium (MEM; Thermo Fisher Scientific, Inc., Waltham, MA, USA) supplemented with $10 \%$ fetal bovine serum (Gibco; Thermo Fisher Scientific, Inc.) and antibiotics (10 U/ml penicillin $\mathrm{G}$ and $10 \mu \mathrm{g} / \mathrm{ml}$ streptomycin) (growth medium). Psammaplin A is a natural marine product that was isolated 
from two sponges, Jaspis sp. and Poecillastra wondoensis (17). The other compounds were isolated from a sponge-derived fungus Acremonium sp. and their configurations were determined by $\mathrm{CD}$ spectroscopic data, along with comparison of ${ }^{1} \mathrm{H}$ and ${ }^{13} \mathrm{C}$ spectroscopic data (25). All chemicals used in the study were a gift from Professor Jung (College of Pharmacy, Pusan National University, Busan, Korea). The natural marine products were dissolved in anhydrous ethanol to make a $10 \mathrm{mg} / \mathrm{ml}$ stock solution. Subsequent dilutions were made in Dulbecco's modified Eagle's medium.

Bacterial strains and growth conditions. $V$. vulnificus strain MO6-24/O used in the present study was isolated from patients $(9,10)$ and provided by Professor Sang Ho Choi (Seoul National University, Seoul, Korea). The V. vulnificus bacteria were grown to $\log$ phase at $30^{\circ} \mathrm{C}$ in Luria-Bertani medium (produced in the laboratory) supplemented with $2.0 \% \mathrm{NaCl}$ LBS medium, after which they were diluted to $6 \times 10^{8} \mathrm{CFU} / \mathrm{ml}$ in LBS medium, and then centrifuged for $3 \mathrm{~min}$ at 2,500 $\mathrm{xg}$ and resuspended in antibiotic-free MEM medium prior to infection of INT-407 cells. The concentration of bacteria was confirmed via viable colony counting conducted on LBS agar.

In vitro broth cultures of $V$. vulnificus. The $V$. vulnificus inoculum size was $6 \times 10^{8} \mathrm{CFU} / \mathrm{ml}$. Variable concentrations of natural pure compounds $1,4,6,8$ and $10(1,5,10,12.5,20,25$, $40,50,75$ and $100 \mu \mathrm{g} / \mathrm{ml}$ ) were solubilized in $20 \mathrm{ml}$ of growth medium (2\% $\mathrm{NaCl} \mathrm{LBS})$ and then tested for their ability to alter bacterial growth by spectrometry $\left(\mathrm{OD}_{540}\right)$. This was conducted by culturing $V$. vulnificus for $0-13 \mathrm{~h}$ in the presence of $50 \mu \mathrm{g} / \mathrm{ml}$ psammaplin A or $0-100 \mu \mathrm{g} / \mathrm{ml}$ psammaplin A for $13 \mathrm{~h}$ at $37^{\circ} \mathrm{C}$ in $2 \% \mathrm{NaCl} \mathrm{LB}$ medium, and bacterial growth was evaluated by measuring the optical density at $540 \mathrm{~nm}$ $\left(\mathrm{OD}_{540}\right)$. The $V$. vulnificus cultures were then incubated with aeration at $150 \mathrm{rpm}$ using a gyratory shaker for $5 \mathrm{~h}$ at $37^{\circ} \mathrm{C}$.

Infection protocol. INT-407 human epithelial cells were infected with $V$. vulnificus as previously described $(9,10)$. Briefly, INT-407 cells were grown in growth medium at $37^{\circ} \mathrm{C}$ in a $5 \% \mathrm{CO}_{2}$ incubator. Next, the cells were seeded onto 6 -well (8x10 ${ }^{5}$ cells/well) and 96-well $\left(2 \times 10^{4}\right.$ cells/well) culture plates and then cultured for $24 \mathrm{~h}$ in antibiotic-free growth medium. Prior to infection, the bacteria were centrifuged for $3 \mathrm{~min}$ at 2,500 x g, resuspended and adjusted to $6 \times 10^{8} \mathrm{CFU} / \mathrm{ml}$ in antibiotic-free MEM medium. The bacterial suspensions were then added to psammaplin A-treated or untreated-epithelial cells at various multiplicities of infection (MOI; the ratio of the number of bacteria to the number of epithelial cells), after which the infected cells were incubated for 1-4 $\mathrm{h}$ in antibiotic-free growth medium at $37^{\circ} \mathrm{C}$ under $5 \% \mathrm{CO}_{2}$.

Cytotoxicity assay. The bacteria-infected INT-407 cell cultures were aliquoted into a 96-well tissue culture plate (Nunc, Roskilde, Denmark) as previously described $(9,10)$. The cytotoxicity was then determined by measuring the activity of lactate hydrogenase (LDH) in the supernatant using a cytotoxicity detection kit (Roche, Mannheim, Germany). The cytotoxic level was expressed as a percentage relative to the total LDH activity of cells that were completely lysed by $1 \%$ Triton X-100 $(9,10)$.

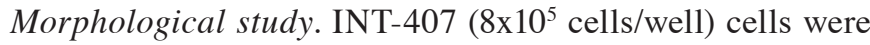
incubated with bacteria in a 6 -well plate for $3 \mathrm{~h}$ at an MOI of 10 , after which the cells were washed with phosphate-buffered saline (PBS). The cells were then fixed with $4 \%$ para-formaldehyde (Sigma-Aldrich, St. Louis, MO, USA) for $10 \mathrm{~min}$ at room temperature, washed and completely dried. Next, the cells were stained with Giemsa solution (Molecular Probes, Thermo Fisher Scientific, Inc.) for $1 \mathrm{~h}$ at room temperature. The cells were then washed twice with distilled water and dried, after which the images of the specimens were acquired using a microscope (Olympus IX 71, Tokyo, Japan).

Survival of V.vulnificus-infected mice. A total of 35 female ICR mice (Samtaco Bio Korea, Gyounggi-do, Korea; age, 8 weeks; weight, 20-22 g) that were housed under specific-pathogen free conditions were used for all experiments. They were maintained at $24^{\circ} \mathrm{C}$ with a relative humidity of $50 \%$, under a 12-h light/dark cycle. The mice had access to food and water ad libitum. The present study was approved by Korea University (Seoul, Korea). The mice were intraperitoneally infected with $0.1 \mathrm{ml}$ of $250 \mu \mathrm{g}$ iron dextran (Sigma-Aldrich) 30 min prior to injection with $V$. vulnificus. Next, the mice were intraperitoneally injected with $1 \times 10^{3} \mathrm{CFU} / 0.1 \mathrm{ml} \mathrm{V}$. vulnificus . The use of iron dextran produces a useful model to investigate systemic disease that results from $V$. vulnificus infection. The mice were administered $0.2 \mathrm{ml}$ psammaplin A (DCM 1-9-1) solution $(5,10,25$ or $50 \mu \mathrm{g}$ per mouse) or a PBS intraperitoneally (control), after which their survival status was assessed every hour for $24 \mathrm{~h}$.

Quantitative analysis of bacteria in tissues. The $V$. vulnificus-inoculated mice were sacrificed by cervical dislocation $7 \mathrm{~h}$ after infection. A ventral incision was made to observe the abdomen of the infected mice treated with or without psammaplin A (Nikon D60; Nikon Corporation, Tokyo, Japan), and the spleen, liver and small intestine lesions were then aseptically removed. The removed specimens were homogenized in $2 \mathrm{ml}$ PBS using glass tissue homogenizers, after which the homogenates were diluted in PBS and plated on $2 \% \mathrm{NaCl} \mathrm{HI}$ agar. The samples were then incubated at $37^{\circ} \mathrm{C}$ for $12 \mathrm{~h}$ and bacterial colonies were counted.

Statistical analysis. The data were analyzed with Microsoft Excel (Microsoft Corporation, Redmond, WA, USA). Student's t-test and one-way analysis of variance followed by the Bonferroni method were employed to identify statistical differences between the values of the various experimental and control groups. $\mathrm{P}<0.05$ was considered to indicate a statistically significant difference.

\section{Results}

Psammaplin A suppresses V. vulnificus-induced cytotoxicity in human epithelial cells. Twelve pure compounds were isolated from natural marine products, and their structures were characterized as previously described (17,25) (Fig. 1). The inhibitory effects of these compounds were determined on $V$. vulnificus-induced cytotoxicity (Fig. 2). INT-407 cells were infected with $V$. vulnificus at an MOI of 10 for $3 \mathrm{~h}$ in the presence or absence of the 12 marine product-derived 


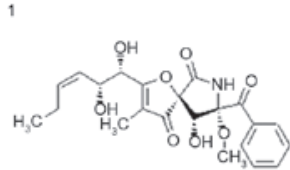

Pseurotin A

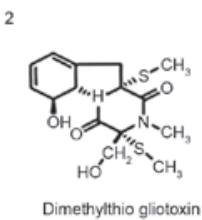

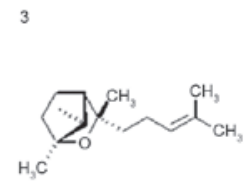

Lignoren

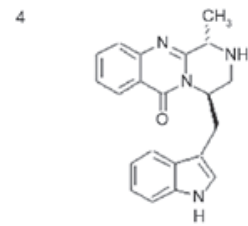

Fumiquinazolin<smiles>C/C(=C\Cc1c(O)c(Cl)c(C)c(C=O)c1O)CC/C=C(\C)[C@H]1CC(=O)C(C)(C)O1</smiles>

Ascofuranone<smiles>C/C(=C\Cc1c(O)cc(C)c(C=O)c1O)CC/C=C(\C)CCC(O)C(C)(C)O</smiles>

Cylindrocarpol<smiles>O=C(NCCSSCCNC(=O)/C(Cc1ccc(O)c(Br)c1)=N/O)/C(Cc1ccc(O)c(Br)c1)=N/O</smiles>

Psammaplin A<smiles>CC(/C=C/C1(C)C(C)C(=O)CC[C@H]1C)=C\Cc1c(O)cc(C)c(C=O)c1O</smiles>

Cylindrol B

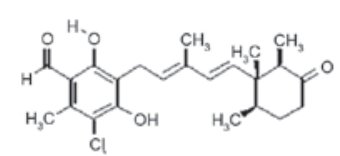

Ascochlorin<smiles>[R]C(C[C@]1(C)C(C)CCC(=O)C1(C)C)/C(C)=C/Cc1c(O)c(Cl)c(C)c(C=O)c1O</smiles>

Ilicicolin C

10

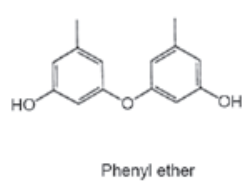<smiles>C/C(=C\Cc1c(O)cc(C)c(C=O)c1O)CC/C=C(\C)CCC(O)C(C)(C)O</smiles>

Cylindrocarpol

Figure 1. Structures and names of 12 pure compounds isolated from natural marine products.

A

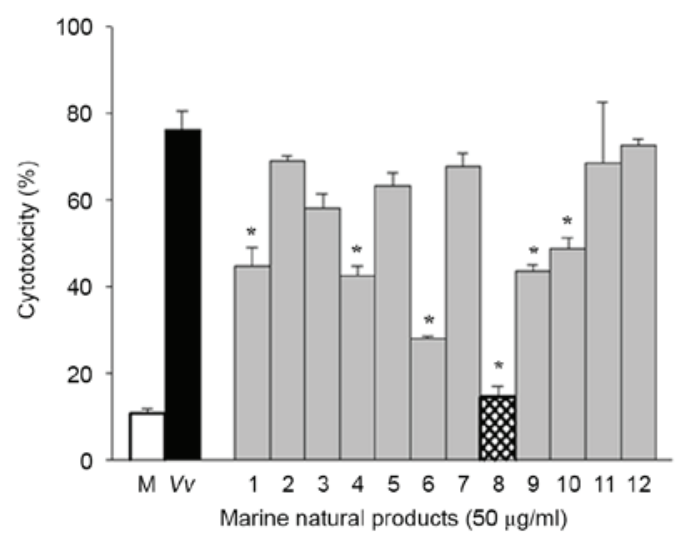

B

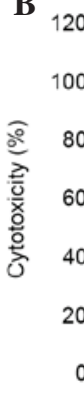

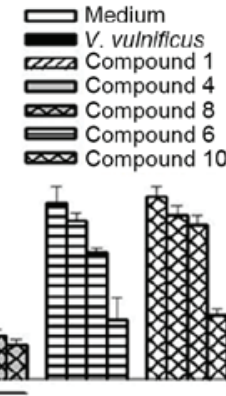

$12 . \overline{25 \quad 50} 100$

Marine natural products $(\mu \mathrm{g} / \mathrm{ml})$

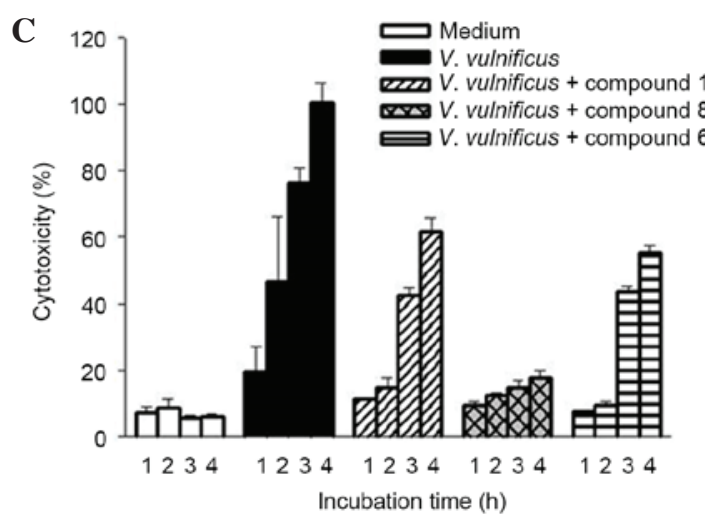

Figure 2. Effects of psammaplin A, a natural marine product on Vibrio vulnificus-induced cytotoxicity in human epithelial cells. (A) INT-407 cells were infected with $\mathrm{V}$. vulnificus for $3 \mathrm{~h}$ at an MOI of 10 in the presence or absence of 12 natural marine products (50 $\mu \mathrm{g} / \mathrm{ml})$, and cytotoxicity was determined using the lactase dehydrogenase release assay. The white bars indicate non-infected cells; black, infected but not treated with natural marine products; grey, infected and treated with natural marine products; checkered, infected, treated with psammaplin A. *P<0.05 vs. infected but untreated group. (B) INT-407 cells were infected with $V$. vulnificus for $3 \mathrm{~h}$ at an MOI of 10 in the presence of compounds $1,4,6,8$ and $10(0,12.5,25,50 \mathrm{and} 100 \mu \mathrm{g} / \mathrm{ml})$. (C) INT-407 cells were infected with $V$. vulnificus at an MOI of 10 for varying times $(1,2,3$ and $4 \mathrm{~h})$ in the presence of compounds 1,6 and 8 . Data are presented as the mean \pm standard error $(\mathrm{n}=3)$ for all experiments. MOI, multiplicity of infection. 


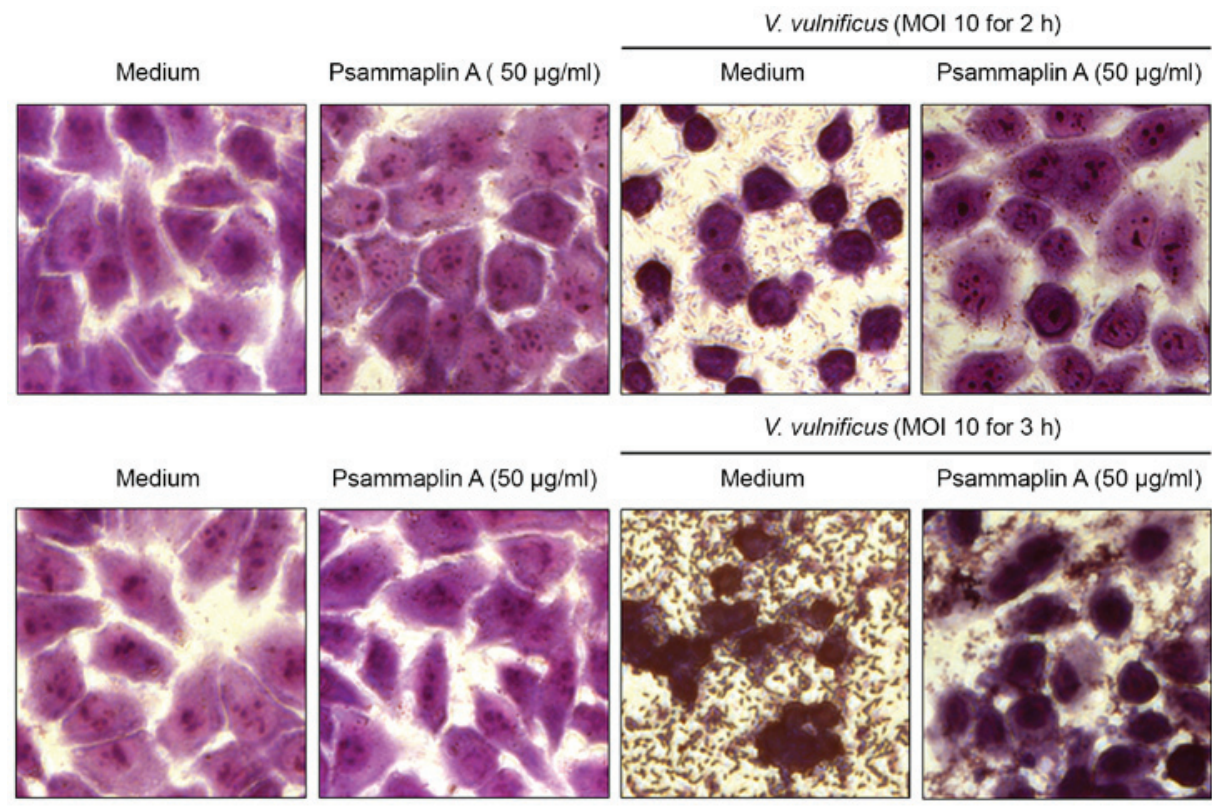

Figure 3. Psammaplin A protects human epithelial cells against Vibrio vulnificus-induced cellular damage. INT-407 cells (8x10 $0^{5}$ cells/well) were incubated with $V$. vulnificus for 2 or $3 \mathrm{~h}$ at MOI 10 in the absence or presence of psammaplin A $(50 \mu \mathrm{g} / \mathrm{ml})$ in six-well plates. Culture plates were then centrifuged, washed twice with pre-warmed PBS (pH 7.4), and fixed with 4\% paraformaldehyde. Next, cells were washed twice with PBS and then stained with Giemsa solution. Images of the specimens were acquired using a microscope (magnification, x400). PBS, phosphate-buffered saline; MOI, multiplicity of infection.

A

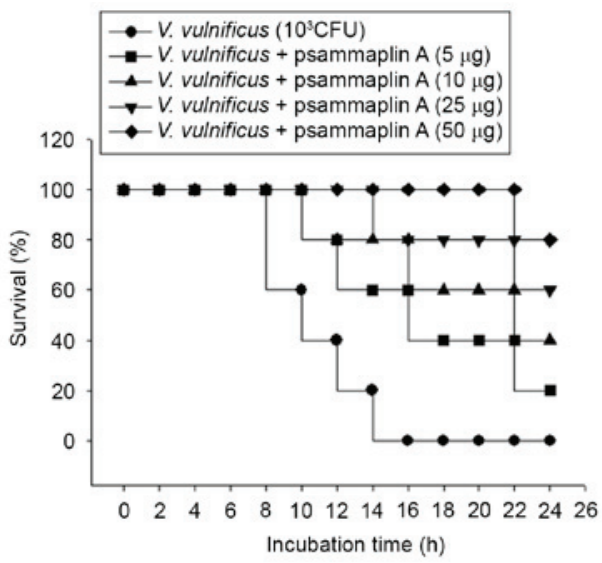

C

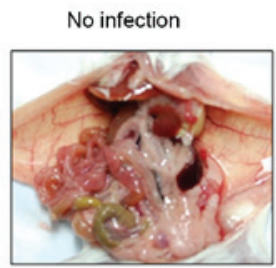

B
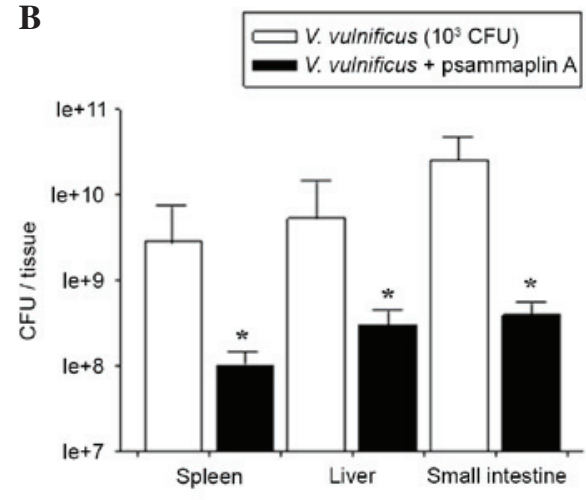

V. vulnificus $\left(10^{3} \mathrm{CFU}\right)+$ psammaplin $\mathrm{A}(\mu \mathrm{g})$
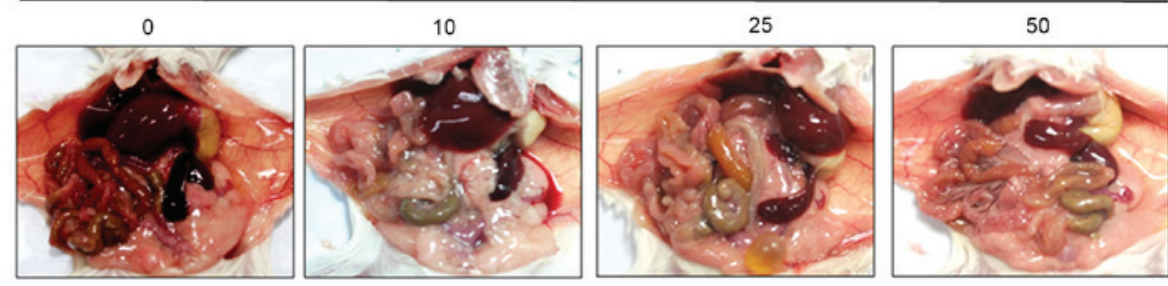

Figure 4. Psammaplin A treatment prolongs the survival of Vibrio vulnificus-inoculated mice. (A) Survival of V. vulnificus-inoculated mice. ICR female mice ( $\mathrm{n}=5$ per group) were intraperitoneally inoculated with $10^{3} \mathrm{CFU}$ V. vulnificus and then treated with psammaplin A (5-50 $\mu \mathrm{g}$ per mouse). Survival of the mice was recorded every hour for $24 \mathrm{~h}$. (B) Determination of the number of $V$. vulnificus colonies recovered from various tissues. ICR female mice (n=5 per group) were intraperitoneally inoculated with $10^{3} \mathrm{CFU}$ V. vulnificus, and treated with or without psammaplin A (5-50 $\mu \mathrm{g}$ per mouse). At $7 \mathrm{~h}$ after $V$. vulnificus infection, the spleen, liver and small intestine were excised. Specimens were homogenized, diluted, plated on $2 \% \mathrm{NaCl} \mathrm{HI}$ agar plates, incubated at $37^{\circ} \mathrm{C}$ for $12 \mathrm{~h}$, and then the number of bacterial colonies was counted. Data are presented as the mean \pm standard error. ${ }^{*} \mathrm{P}<0.05$ vs. infected but untreated group. (C) Opened abdomen of V. vulnificus-infected mice treated with or without psammaplin A treatment observed using a digital camera (Nikon D60). 

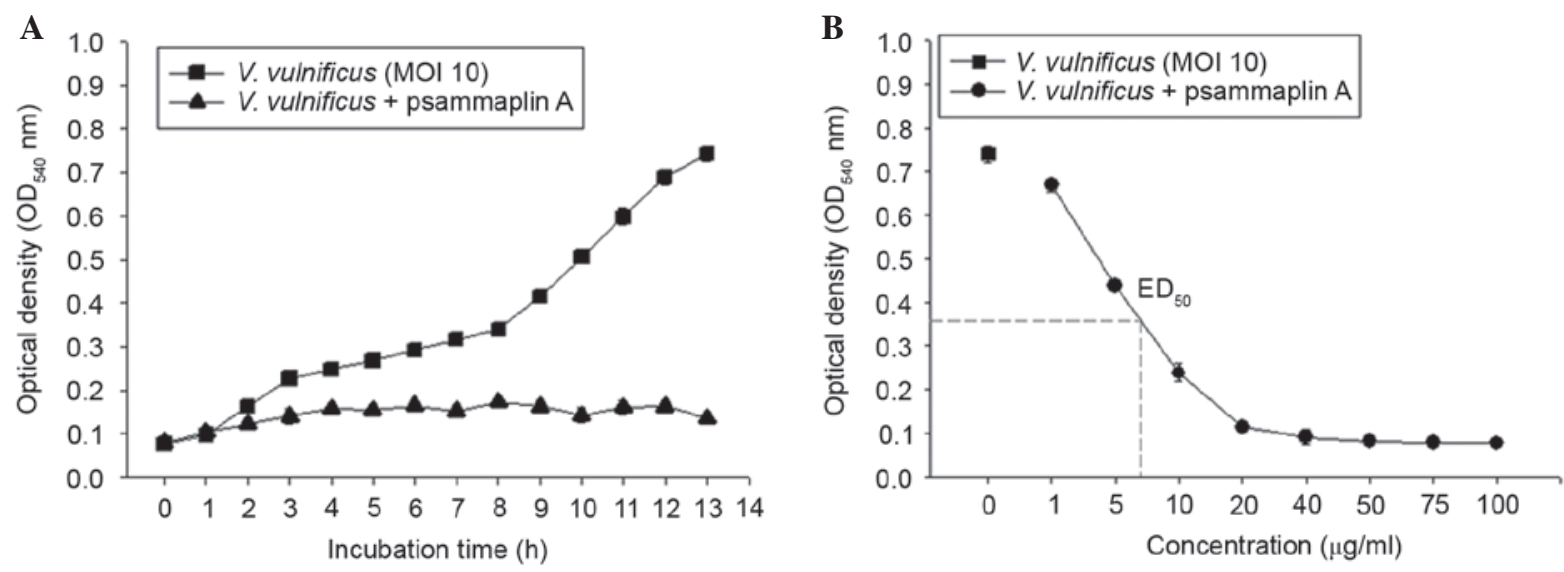

Figure 5. Inhibition of Vibrio vulnificus growth by psammaplin A. (A) V. vulnificus was cultured for 0-13 h with $50 \mu \mathrm{g} / \mathrm{ml} \mathrm{psammaplin} \mathrm{A} \mathrm{and} \mathrm{(B)} 0-100 \mu \mathrm{g} / \mathrm{ml}$ psammaplin $\mathrm{A}$ for $13 \mathrm{~h}$ at $37^{\circ} \mathrm{C}$ in $2 \% \mathrm{NaCl}$ Luria-Bertani medium, and bacterial growth was evaluated by measuring the optical density at $540 \mathrm{~nm}\left(\mathrm{OD}_{540}\right)$. MOI, multiplicty of infection; $\mathrm{OD}_{540}$, optical density at $540 \mathrm{~nm}$.

compounds. Then, the cytotoxicities of the compounds were evaluated in cells using LDH assays. As shown in Fig. 2A, there was significantly decreased cytotoxicity in cells treated with compounds $1,4,6,8,9$ and 10 compared with the untreated cells infected with $V$. vulnificus, indicating that these compounds have inhibitory effects on $V$. vulnificus-induced cytotoxicity. Treatment with these compounds significantly inhibited the cytotoxicity of $V$. vulnificus in a concentration- and time-dependent manner (Fig. 2B and C). Of these compounds, psammaplin A (compound 8) had the strongest inhibitory effect on the $V$. vulnificus-induced cytotoxicity.

To confirm the inhibitory effects of psammaplin A on the V. vulnificus-induced cytotoxicity of INT-407 cells, the size and morphology of nuclei were assessed using a microscope (Fig. 3). INT-407 cells infected with V. vulnificus at an MOI of 10 for 2-3 h showed typical phenotypic features of cell death, such as cytoplasmic loss and cellular damage, while treatment with psammaplin A reversed that phenotype. Psammaplin A ameliorated the significant cellular damage at $3 \mathrm{~h}$ after infection with $V$. vulnificus. These results suggest that psammaplin A inhibits the cytotoxicity against host cells induced by $V$. vulnificus infection.

Psammaplin A treatment prolongs the survival of $V$. vulnificus-infected mice. To investigate whether psammaplin A prolonged survival, mice were infected with $V$. vulnificus and administered psammaplin A (0-50 $\mu$ g per mouse). Mice inoculated intraperitoneally with $1 \times 10^{3} \mathrm{CFU} V$. vulnificus all died within $16 \mathrm{~h}$. However, psammaplin A treatment of $V$. vulnificus-infected mice increased the survival rate. Following psammaplin A treatment, four out of five mice infected with $V$. vulnificus (50 $\mu \mathrm{g}$ per mouse) survived for $24 \mathrm{~h}$ (Fig. 4A).

To investigate the effects of psammaplin A treatment on the growth of $V$. vulnificus in vivo, mice were intraperitoneally infected with $1 \times 10^{3} \mathrm{CFU}$ V. vulnificus and administered psammaplin A $(0,10,25$ and $50 \mu \mathrm{g}$ per mouse). After $7 \mathrm{~h}$, several tissue samples, including from the spleen, liver and small intestine were excised from the mice, and the number of $V$.vulnificus colonies in each tissue was evaluated. Fig. 4B shows that the number of $V$. vulnificus colonies was significantly reduced in all tissue samples isolated from psammaplin A-treated mice compared with the number of $V$. vulnificus colonies isolated from untreated controls. In addition, the necropsy results of V. vulnificus-infected mice at $7 \mathrm{~h}$ post infection showed edema, hemorrhage, vasodilation and necrosis in the intestines, livers and spleens isolated from the untreated mice. However, the tissue samples from the psammaplin A-treated mice did not show any of the symptoms observed in the tissues of untreated mice (Fig. 4C). These results suggest that psammaplin A significantly suppresses the growth of $V$. vulnificus and the associated pathology in vitro and in vivo.

Psammaplin A strongly inhibits $V$. vulnificus growth in vitro. To investigate the antibacterial activities of psammaplin A against $V$. vulnificus, $V$. vulnificus was incubated in the presence or absence of psammaplin A $(0-100 \mu \mathrm{g} / \mathrm{ml})$ for $0-13 \mathrm{~h}$. As shown in Fig. 5, the bacterial numbers of $V$. vulnificus increased in an incubation time-dependent manner. However, psammaplin A treatment inhibited the growth of $V$. vulnificus in a concentration-dependent manner. These findings suggest that psammaplin A significantly inhibited the growth of $V$. vulnificus.

\section{Discussion}

$V$. vulnificus, which is a gram-negative bacterium, causes fatal septicemia in individuals with liver cirrhosis, diabetes, hemochromatosis or immunocompromised conditions $(26,27)$. Infection with $V$. vulnificus causes extensive cellular damage and $>50 \%$ of patients with $V$. vulnificus-induced septicemia die. Recent studies revealed that hemolysin produced by $V$. vulnificus (VvhA) induces nuclear factor $\kappa$-light-chain-enhancer of activated $\mathrm{B}$ cells-dependent mitochondrial cell death via lipid raft-mediated reactive oxygen species production in human epithelial cells (28). Therefore, there is an increasing requirement for effective antimicrobial agents for the treatment of $V$. vulnificus infections. Psammaplin A was first isolated from the Psammaplinaplysilla sponge and it was known to impede bacterial growth by inhibiting the activities of several key enzyme-mediated processes in prokaryotic systems including DNA replication, microbial detoxification and epigenetic control of gene expression. The results of this study proved 
that the marine sponge-derived psammaplin A exerted strong inhibitory activity against $V$. vulnificus in epithelial cells and mice.

The 12 pure compounds isolated from natural marine products were incubated with $V$. vulnificus-infected epithelial cells . Among the compounds, psammaplin A exhibited lower cytotoxicity than the other 11 compounds. In addition, psammaplin A treatment exerted inhibitory effects on $V$. vulnificus-induced cytotoxicity in a concentration- and time-dependent manner, indicating that it prevented the $V$. vulnificus-induced epithelial cell death. Moreover, cytoplasmic loss and cellular damage were not observed in $V$. vulnificus-infected epithelial cells treated with psammaplin A. Furthermore, administration of psammaplin A to $V$. vulnificus-infected mice improved their survival rate compared with that of untreated mice. The number of $V$. vulnificus colonies in the spleens, livers and small intestines of psammaplin A-treated mice was significantly lower than the number of $V$. vulnificus colonies in the untreated mice. Unlike the untreated mice, there was no edema, hemorrhage, vasodilation or necrosis in the intestine, liver and spleen isolated from the psammaplin A-treated mice. Treatment with psammaplin A effectively suppressed the growth of $V$. vulnificus throughout the incubation time in a dose-dependent manner.

The underlying mechanism of the potent anti- $V$. vulnificus activity of psammaplin A remains unclear. Previously, psammaplin A was reported to possess antibacterial activity against gram-positive bacteria, including MRSA, possibly by inhibiting DNA synthesis and gyrase activity. The anti- $V$. vulnificus activity of psammaplin A warrants further investigation to determine the specific underlying mechanism.

In conclusion, the results of this study clearly demonstrated that psammaplin A exerted strong inhibitory activity against $V$. vulnificus in vitro and in vivo. These findings suggest that psammaplin A may be a candidate therapeutic agent for the treatment of $V$. vulnificus-related diseases.

\section{Acknowledgements}

This study was supported by the Agriculture, Food and Rural Affairs Research Center Support Program, Ministry of Agriculture, Food and Rural Affairs, Republic of Korea (to Professor Tae Sung Kim).

\section{References}

1. Ikeda T, Kanehara S, Ohtani T and Furukawa F: Endotoxin shock due to Vibrio vulnificus infection. Eur J Dermatol 16: 423-427, 2006.

2. Powell JL, Wright AC, Wasserman SS, Hone DM and Morris JG Jr: Release of tumor necrosis factor alpha in response to Vibrio vulnificus capsular polysaccharide in vivo and in vitro models. Infect Immun 65: 3713-3718, 1997.

3. Wright AC, Powell JL, Kaper JB and Morris JG Jr: Identification of a group 1-like capsular polysaccharide operon for Vibrio vulnificus. Infect Immun 69: 6893-6901, 2001.

4. Simpson LM and Oliver JD: Siderophore production by Vibrio vulnificus. Infect Immun 41: 644-649, 1983.

5. Gray LD and Kreger AS: Purification and characterization of an extracellular cytolysin produced by Vibrio vulnificus. Infect Immun 48: 67-72, 1985.

6. Kim CM, Park RY, Chun HJ, Kim SY, Rhee JH and Shin SH: Vibrio vulnificus metalloprotease VvpE is essentially required for swarming. FEMS Microbiol Lett 269: 170-179, 2007.
7. Lee JH, Rho JB, Park KJ, Kim CB, Han YS, Choi SH, Lee KH and Park SJ: Role of flagellum and motility in pathogenesis of Vibrio vulnificus. Infect Immun 72: 4905-4910, 2004.

8. Gulig PA, Bourdage KL and Starks AM: Molecular pathogenesis of Vibrio vulnificus. J Microbiol 43: 118-131, 2005.

9. Lee JH, Kim MW, Kim BS, Kim SM, Lee BC, Kim TS and Choi SH: Identification and characterization of the Vibrio vulnificus rtxA essential for cytotoxicity in vitro and virulence in mice. J Microbiol 45: 146-152, 2007.

10. Lee BC, Lee JH, Kim MW, Kim BS, Oh MH, Kim KS, Kim TS and Choi SH: Vibrio vulnificus rtxE is important for virulence and its expression is induced by exposure to host cells. Infect Immun 76: 1509-1517, 2008.

11. Lee BC, Choi SH and Kim TS: Vibrio vulnificus RTX toxin plays an important role in the apoptotic death of human intestinal epithelial cells exposed to Vibrio vulnificus. Microbes Infect 10: 1504-1513, 2008.

12. Espat NJ, Auffenberg T, Abouhamze A, Baumhofer J, Moldawer LL and Howard RJ: A role for tumour necrosis factor-alpha in the increased mortality associated with Vibrio vulnificus infection in the presence of hepatic dysfunction. Ann Surg 223: 428-433, 1996.

13. Shin SH, Shin DH, Ryu PY, Chung SS and Rhee JH: Proinflammatory cytokine profile in Vibrio vulnificus septicemic patients' sera. FEMS Immunol Med Microbiol 33: 133-138, 2002.

14. Jung JH, Sim CJ and Lee CO: Cytotoxic compounds from a two-sponge association. J Nat Prod 58: 1722-1726, 1995.

15. Quiňoà E: C.P. Crew: Phenolic constituents of psammaplysilla. Tetrahedron Lett 28: 3229-3233, 1987.

16. Kim D, Lee IS, Jung JH and Yang SI: Psammaplin A, a natural bromotyrosine derivative from a sponge, possesses the antibacterial activity against methicillin-resistant Staphylococcus aureus and the DNA gyrase-inhibitory activity. Arch Pharm Res 22: 25-29, 1999

17. Park Y, Liu Y, Hong J, Lee CO, Cho H, Kim DK, Im KS and Jung JH: New bromotyrosine derivatives from an association of two sponges, Jaspis wondoensis and Poecillastra wondoensis. J Nat Prod 66: 1495-1498, 2003.

18. Kim D, Lee IS, Jung JH, Lee CO and Choi SU: Psammaplin a natural phenolic compound, has inhibitory effect on human topoisomerase II and is cytotoxic to cancer cells. Anticancer Res 19: 4085-4090, 1999.

19. Shin J, Lee HS, Seo Y, et al: New bromotyrosine metabolites from the sponge Aplysinella rhax. Tetrahedron 26: 9071-9077, 2000.

20. Liu S, Fu X, Schmitz FJ and Kelly-Borges M: Psammaplysin F, a new bromotyrosine derivative from a sponge, Aplysinella $\mathrm{sp}$. J Nat Prod 60: 614-615, 1997.

21. Tabudravu JN, Eijsink VG, Gooday GW, Jaspars M, Komander D, Legg M, Synstad B and van Aalten DM: Psammaplin A, a chitinase inhibitor isolated from the Fijian marine sponge Aplysinella rhax. Bioorganic Med Chem 10: 1123-1128, 2002.

22. Piña IC, Gautschi JT, Wang GY, Sanders ML, Schmitz FJ, France D, Cornell-Kennon S, Sambucetti LC, Remiszewski SW, Perez LB, et al: Psammaplins from the sponge Pseudoceratina purpurea: Inhibition of both histone deacetylase and DNA methyltransferase. J Org Chem 68: 3866-3873, 2003.

23. Nicolaou KC, Hughes R, Pfefferkorn JA, Barluenga S and Roecker AJ: Combinatorial synthesis through disulfide exchange: Discovery of potent psammaplin A type antibacterial agents active against methicillin-resistant Staphylococcus aureus (MRSA). Chemistry 7: 4280-4295, 2001.

24. Nicolaou KC, Hughes R, Pfefferkorn JA and Barluenga S: Optimization and mechanistic studies of psammaplin A type antibacterial agents active against methicillin-resistant Staphylococcus aureus (MRSA). Chemistry 7: 4296-4310, 2001.

25. Zhang P, Bao B, Dong HT, Hong J, Lee HJ, Yoo ES, Bae KS and Jung JH: Anti-inflammatory sesquiterpenoids from a sponge-derived fungus Acremonium sp. J Nat Prod 72: 270-275, 2009.

26. Linkous DA and Oliver JD: Pathogenesis of Vibrio vulnificus. FEMS Microbiol Lett 174: 207-214, 1999.

27. Strom MS and Paranjpye RN: Epidemiology and pathogenesis of Vibrio vulnificus. Microbes Infect 2: 177-188, 2000.

28. Lee SJ, Jung YH, Oh SY, Song EJ, Choi SH and Han HJ: Vibrio vulnificus VvhA induces NF-kB-dependent mitochondrial cell death via lipid raft-mediated ROS production in intestinal epithelial cells. Cell Death Dis 6: 1655, 2015. 